\title{
Pengaruh lama aplikasi bahan remineralisasi casein phosphopeptide-amorphous calcium phosphate fluoride (CPP-ACPF) terhadap kekerasan email
}

\author{
Miftah Wiryani*, Billy Sujatmiko**, Rini Bikarindrasari ${ }^{\star * *}$ \\ *Program Studi Kedokteran Gigi, Fakultas Kedokteran, Universitas Sriwijaya, Palembang, Sumatera Selatan, Indonesia \\ ${ }^{* *}$ Bagian Konservasi Gigi-RSMH, Program Studi Kedokteran Gigi, Fakultas Kedokteran, Universitas Sriwijaya, Palembang, Sumatera \\ Selatan, Indonesia \\ ***Bagian Konservasi Gigi, Program Studi Kedokteran Gigi, Fakultas Kedokteran, Universitas Sriwijaya, Palembang, \\ Sumatera Selatan, Indonesia \\ *JI Raya Palembang-Prabumulih KM.32 Indralaya, Palembang, Sumatera Selatan, Indonesia; e-mail: miftahwiryani@ymail.com
}

Submisi: 19 Mei 2016; Penerimaan: 15 Juni 2016

\begin{abstract}
ABSTRAK
Proses remineralisasi dapat meningkatkan kekerasan email yang menurun akibat demineralisasi. Bahan remineralisasi yang ideal adalah CPP-ACPF. Terdapat perbedaan lama aplikasi CPP-ACPF dalam berbagai penelitian, selain itu total lama aplikasi yang dibutuhkan CPP-ACPF dalam mekanisme remineralisasi belum diketahui. Penelitian ini dilakukan untuk mengetahui pengaruh lama aplikasi CPP-ACPF terhadap kekerasan email Tiga puluh mahkota gigi premolar yang ditanam dalam resin akrilik self cure dibagi menjadi lima kelompok, kemudian dilakukan proses demineralisasi. Kekerasan email kemudian diukur menggunakan alat Vickers Hardness Tester. Proses remineralisasi menggunakan CPP-ACPF dilakukan pada masing-masing kelompok dalam berbagai lama aplikasi yaitu 3 menit, 15 menit, 30 menit, 60 menit, serta perendaman dalam saliva buatan selama 60 menit (kontrol). Kekerasan email kemudian diukur kembali (posttest). Data diuji secara statistik menggunakan t-test berpasangan, one-way ANOVA dan post hoc Bonferroni. Hasil paired t-test menunjukkan bahwa seluruh kelompok, kecuali kelompok kontrol, mengalami peningkatan rata-rata kekerasan email secara signifikan. Hasil uji one-way ANOVA pada pretest menunjukkan tidak ada perbedaan kekerasan email yang signifikan. Hasil uji one-way ANOVA pada posttest menunjukkan terdapat perbedaan kekerasan email yang signifikan. Hasil uji post Hoc Bonferroni menunjukkan bahwa terdapat perbedaan kekerasan email yang signifikan pada seluruh kelompok perlakuan terhadap kelompok kontrol, tetapi perbedaan kekerasan email antara kelompok lama aplikasi 3 menit dengan 15 menit, antara lama aplikasi 15 menit dengan 30 menit, serta antara lama aplikasi 30 menit dengan 60 menit tidak menunjukkan perbedaan kekerasan email yang signifikan. Kesimpulan penelitian ini adalah berbagai lama aplikasi CPP-ACPF berpengaruh terhadap peningkatan kekerasan email.
\end{abstract}

Kata kunci: CPP-ACPF, kekerasan email, lama aplikasi, remineralisasi

ABSTRACT: The effect of application time of CPP-ACPF on enamel hardness. Remineralization process can increase the hardness of enamel due to demineralization process. CPP-ACPF is a material used for enhancing remineralization. However, the application time of CPP-ACPF remain controversial among previous studies. This study was aimed to investigate the effect of various application times of CPP-ACPF on enamel hardness. Thirty premolar teeth were mounted on self cure acrylic resin, and were divided into 5 groups. Demineralization process was performed, and enamel hardness (pre-est) was measured by Vickers Hardness Tester. Remineralization was performed using CPP-ACPF in various application times: 3, 15, 30, 60 minutes, and the control group was only immersed in artificial saliva for 60 minutes, then enamel hardness was measured (posttest). Data were analyzed using paired t-test; one-way ANOVA, and post-hoc Bonferroni. The result of paired t-test showed that all the groups, except the control group, have an increasing enamel hardness that was statistically significant. One-way ANOVA results showed no statistically significant difference among the groups at pretest, but one-way ANOVA results showed statistically significant difference at posttest. Post hoc Bonferroni showed that the significantly difference at posttest occurred between all the treatment groups against the control group, but there were no significant differences between the 3 minutes group to 15 minutes group, between 15 minutes group to 30 minutes group, and between 30 minutes group to 60 minutes group. It was concluded that various application times of CPP-ACPF had an effect on increasing enamel hardness.

Keywords: CPP-ACPF, enamel hardness, application time, remineralization 


\section{PENDAHULUAN}

Email merupakan struktur terluar dari mahkota gigi yang tersusun atas kristal hidroksiapatit. $^{1}$ Mineral penyusun hidroksiapatit dapat terlepas dari permukaan email yang disebut dengan proses demineralisasi. ${ }^{2}$ Demineralisasi dapat menimbulkan porus, permukaan email kasar, dan kekerasan email menurun. ${ }^{3,4,5}$ Kerugian akibat proses demineralisasi dapat diperbaiki melalui proses remineralisasi. ${ }^{2}$

Remineralisasi ialah proses ketika kristal apatit terbentuk kembali pada permukaan email, sehingga kekerasan email yang menurun akibat demineralisasi dapat meningkat kembali. ${ }^{2}$ Proses remineralisasi dapat terjadi secara alami atau dipercepat menggunakan bahan remineralisasi. Syarat bahan remineralisasi yang ideal adalah dapat melepaskan ion kalsium dan fosfat, mencegah pembentukan kalkulus, serta bekerja baik pada kondisi saliva yang sedikit dan pada lingkungan yang asam. ${ }^{6,7}$ Bahan dengan kriteria tersebut adalah CPP-ACPF (casein phosphopeptide amorphouscalcium phosphate + fluoride 900 ppm). ${ }^{4,6,8}$

Lama aplikasi minimal CPP-ACPF sesuai anjuran pabrik adalah 3 menit, kemudian sisa di dalam mulut dapat diludahkan dan dianjurkan untuk menghindari pembilasan. Pasien dianjurkan untuk tidak makan dan minum selama 30 menit setelah pemakaian, efek maksimal didapatkan dengan mempertahankan pasta CPP-ACPF selama mungkin di dalam mulut. Anjuran tersebut mengindikasikan bahwa proses remineralisasi oleh CPP-ACPF akan terus terjadi di dalam rongga mulut setelah aplikasi 3 menit. Perbedaan lama aplikasi pasta CPP-ACPF juga terdapat dalam beberapa penelitian. ${ }^{9,10}$ Berbagai penelitian mengindikasikan bahwa CPP-ACPF dapat meningkatkan kekerasan email, tetapi pengaruh aplikasi pasta CPP-ACPF dalam waktu aplikasi yang lebih lama, dan total waktu yang dibutuhkan oleh CPP-ACPF dalam proses remineralisasi masih belum diketahui. ${ }^{6}$ Penelitian ini bertujuan untuk mengetahui pengaruh variasi lama aplikasi bahan remineralisasi CPP-ACPF terhadap kekerasan email.

\section{METODE PENELITIAN}

Subjek penelitian ini adalah 15 gigi premolar pertama dan kedua rahang atas dan rahang bawah yang bebas karies, bebas tambalan dan telah diekstraksi. Gigi dibersihkan, kemudian direndam sterile water dalam plastik klip tertutup dan dibekukan dalam lemari pendingin hingga siap digunakan. ${ }^{11}$ Mahkota gigi dipisahkan dari akar gigi pada bagian cemento enamel junction (CEJ) menggunakan separating disk, kemudian mahkota dipotong secara vertikal pada arah mesiodistal (Gambar 1). Setiap mahkota gigi dapat menghasilkan dua sampel sehingga total berjumlah 30 sampel. ${ }^{12,13}$ Mahkota gigi kemudian ditanam dalam resin akrilik self cure menggunakan cetakan berbentuk tabung dengan diameter $1 \mathrm{~cm}$ dan tinggi $1 \mathrm{~cm}$. Permukaan email diratakan menggunakan amplas ukuran 400, 1000, dan 1500 secara berurutan (Gambar 2). ${ }^{9}$

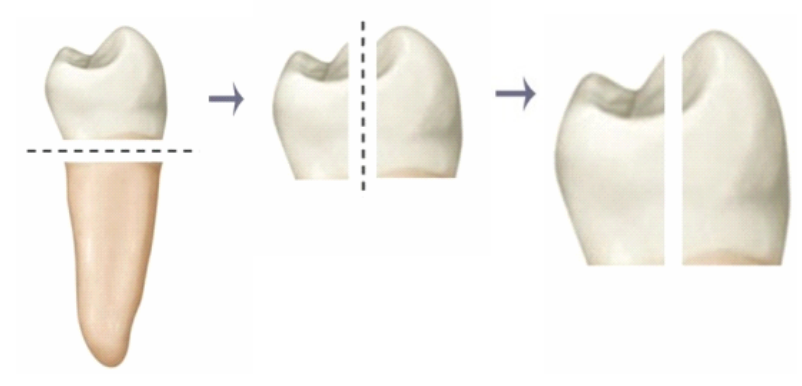

Gambar 1. Pemotongan mahkota gigi

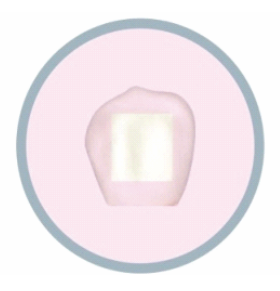

(A)

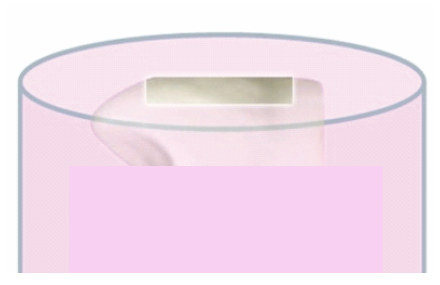

(B)
Gambar 2. Mahkota gigi yang telah ditanam dalam resin akrilik self cure $(A)$ terlihat dari atas, $(B)$ terlihat dari samping

Subjek penelitian dikelompokkan ke dalam 5 kelompok (A, B, C, D, E). Prosedur demineralisasi dilakukan dengan merendam sampel dalam larutan demineralisasi (10 ml/sampel) selama 48 jam pada suhu $37^{\circ} \mathrm{C} . .^{14}$ Larutan demineralisasi dibuat dengan 
mencampurkan 2,2 $\mathrm{mM} \mathrm{CaCl}$ (kalsium klorida); 2,2 $\mathrm{mM} \mathrm{NaH} \mathrm{PO}_{4} \cdot 7 \mathrm{H}_{2} \mathrm{O}$ (monosodium fosfat); $0,05 \mathrm{M}$ asam laktat; dan $\mathrm{pH}$ 4,5 diatur dengan menambahkan $50 \% \mathrm{NaOH}$ (sodium hidroksida). ${ }^{14}$ Tahap selanjutnya adalah pengukuran kekerasan email setelah demineralisasi (pretest) menggunakan alat Vickers Hardness Tester dengan beban $5 \mathrm{~kg}$ selama 15 detik dan dilakukan sebanyak dua titik indentasi. Teraan indentasi intan yang berbentuk belah ketupat diukur diameternya menggunakan alat Zoom Stereo Mikroskop (Olympus SZ61), kemudian nilai kekerasan dihitung sesuai dengan rumus yang telah ditentukan.

Proses remineralisasi dilakukan dengan mengoleskan bahan remineralisasi yaitu pasta CPPACPF pada permukaan sampel. Pasta CPP-ACPF yang digunakan sebanyak $0,22 \mathrm{ml}$. Ukuran tersebut sama dengan ukuran pasta yang dianjurkan oleh pabrik yaitu sebesar biji jagung $(0,25 \mathrm{~g}) \cdot{ }^{15}$ Selama prosedur remineralisasi sampel direndam dalam saliva buatan $(10 \mathrm{ml} / \mathrm{sampel})$ pada suhu $37^{\circ} \mathrm{C} .5,15$ Saliva buatan dibuat dengan mencampurkan 0,65 $\mathrm{g} / \mathrm{l}$ potassium klorida, 0,058 g/ magnesium klorida, 0,165 g/ kalsium klorida, 0,804 g/ dipotassium hidrogen fosfat, $0,365 \mathrm{~g} /$ potassium dihidrogen fosfat, $2 \mathrm{~g} /$ carboxymethyl cellulose, dan 1 liter air. ${ }^{10}$

Prosedur remineralisasi dilakukan dengan lama aplikasi yang bervariasi, yaitu: kelompok A selama 3 menit, kelompok B selama 15 menit, kelompok $C$ selama 30 menit, kelompok $D$ selama 60 menit, dan kelompok $\mathrm{E}$ (kontrol) direndam dalam saliva buatan selama 60 menit Kekerasan permukaan email diuji kembali setelah proses remineralisasi (posttest) menggunakan alat Vickers Hardness Tester.
Analisa data yang dilakukan adalah uji parametrik yang didahului dengan uji normalitas dan uji homogenitas data. Analisa dilanjutkan dengan paired t-test untuk mengetahui perbandingan perubahan kekerasan email di dalam grup sebelum dan setelah aplikasi pasta CPP-ACPF, kemudian dilakukan uji one way ANOVA pada posttest untuk mengetahui signifikansi perbedaan nilai kekerasan email antar grup, dan dilanjutkan dengan uji post hoc Bonferroni.

\section{HASIL PENELITIAN}

Data yang diperoleh dari penelitian ini terdistribusi normal dan bersifat homogen. Hasil paired t-test sebelum dan sesudah aplikasi bahan remineralisasi menunjukkan terdapat perbedaan nilai kekerasan email yang signifikan pada kelompok A, B, C, dan D, tetapi tidak pada kelompok $E$ (kontrol) (Tabel 1).

Tabel 1. Hasil paired t-test

\begin{tabular}{|c|c|c|}
\hline & & Sig. \\
\hline \multirow{2}{*}{ Pair 1} & Kel A (3 menit) - Pretest & 0.001 \\
\hline & Kel A (3 menit) - Posttest & \\
\hline \multirow{2}{*}{ Pair 2} & Kel B (15 menit) - Pretest & 0.000 \\
\hline & Kel B (15 menit) - Posttest & \\
\hline \multirow{2}{*}{ Pair 3} & Kel C (30 menit) - Pretest & 0.000 \\
\hline & Kel C (30 menit) - Posttest & \\
\hline \multirow{2}{*}{ Pair 4} & Kel D (60 menit) - Pretest & 0.000 \\
\hline & Kel D (60 menit) - Posttest & \\
\hline \multirow{2}{*}{ Pair 5} & Kel E (kontrol) - Pretest & 0.056 \\
\hline & Kel E (kontrol) - Posttest & \\
\hline
\end{tabular}

Keterangan: Sig: Significance

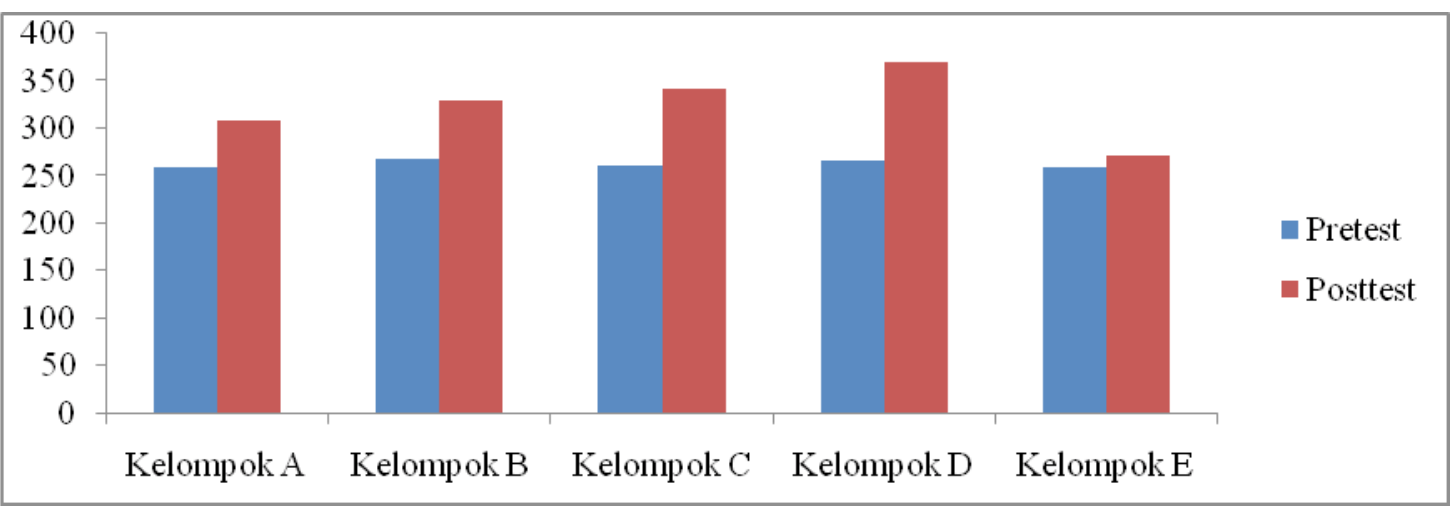

Gambar 3. Grafik nilai rata-rata kekerasan email dan standar deviasi (SD) setelah demineralisasi (pretest), dan setelah remineralisasi menggunakan CPP-ACPF (posttest). 
Tabel 2. Hasil Uji Post-hoc Bonferroni pada Posttest

\begin{tabular}{|c|c|c|c|c|c|}
\hline & $\begin{array}{c}\text { Kelompok } A \\
\text { (3 menit) }\end{array}$ & $\begin{array}{c}\text { Kelompok B } \\
\text { (15 menit) }\end{array}$ & $\begin{array}{c}\text { Kelompok C } \\
\text { (30 menit) }\end{array}$ & $\begin{array}{c}\text { Kelompok D } \\
\text { (60 menit) }\end{array}$ & $\begin{array}{c}\text { Kelompok E } \\
\text { (Kontrol) }\end{array}$ \\
\hline Kelompok A (3 menit) & & 0.712 & $0.049^{*}$ & $0.000^{*}$ & $0.015^{\star}$ \\
\hline Kelompok B (15 menit) & & & 1.000 & $0.006^{*}$ & $0.000^{*}$ \\
\hline Kelompok C (30 menit) & & & & 0.109 & $0.000^{*}$ \\
\hline Kelompok D (60 menit) & & & & & $0.000^{*}$ \\
\hline Kelompok E (Kontrol) & & & & & \\
\hline
\end{tabular}

Keterangan:

*: ada perbedaan yang signifikan

Hasil uji one way ANOVA pada posttest menunjukkan bahwa terdapat perbedaan kekerasan email yang signifikan. Hasil uji post hoc Bonferroni (Tabel 2) menunjukkan bahwa perbedaan nilai kekerasan email yang signifikan terdapat antara kelompok A (3 menit) dengan kelompok $C$ (30 menit), kelompok D (60 menit) dan kelompok $E$ (kontrol), antara kelompok $B$ (15 menit) dengan kelompok $D$ (60 menit) dan kelompok $E$ (kontrol), antara kelompok C (30 menit) dengan kelompok $E$ (Kontrol), serta antara kelompok $D$ (60 menit) dengan kelompok $\mathrm{E}$ (Kontrol). Selain kelompok yang signifikan, terdapat juga perbedaan nilai kekerasan email yang tidak signifikan yaitu antara kelompok $A$ (3 menit) dengan kelompok $B$ (15 menit), antara kelompok $B$ (15 menit) dengan kelompok $C$ (30 menit), serta antara kelompok $C$ (30 menit) dengan kelompok $D$ (60 menit).

\section{PEMBAHASAN}

Mineral pembentuk email gigi yang mengalami perubahan dapat mempengaruhi nilai kekerasan email. ${ }^{2}$ Gambar 3 menunjukkan adanya peningkatan nilai kekerasan email rata-rata setelah dilakukan aplikasi pasta CPP-ACPF (posttest). Signifikansi peningkatan nilai kekerasan email dapat dilihat dengan melakukan paired t-test pada masing-masing kelompok.

Perbedaan kekerasan email yang yang tidak signifikan pada pengujian paired t-test (Tabel 1) hanya terjadi pada kelompok $E$ (kontrol), dikarenakan kelompok E merupakan kelompok yang hanya dilakukan perendaman dalam saliva buatan yang tidak memiliki material penyusun email yang memadai. Saliva buatan juga tidak memiliki unsur casein dan fluor seperti pada CPP-ACPF. Casein mempunyai fungsi untuk mengikat dan mestabilkan ion fosfat, kalsium, dan fluor sehingga dapat dengan mudah membentuk mineral apatit. Fluor berfungsi sebagai ion substitusi dari gugus hidroksil sehingga terbentuk kristal fluorapatit dengan ukuran mineral yang lebih besar dan lebih stabil daripada hidroksiapatit, sehingga perubahan nilai kekerasan email pada kelompok perlakuan menjadi jauh lebih besar dibandingkan dengan kelompok kontrol..$^{20}$ Perbedaan nilai kekerasan yang signifikan pada paired t-test menunjukkan bahwa bahan remineralisasi CPP-ACPF terbukti efektif dalam meningkatkan proses remineralisasi email yang terlihat signifikan dimulai dari lama aplikasi 3 menit hingga lama aplikasi 60 menit. Uji one way ANOVA dan post hoc Bonferroni pada posttest dilakukan untuk melihat lebih detail mengenai perubahan nilai kekerasan antar kelompok setelah perlakuan.

Hasil uji one way ANOVA pada posttest (Tabel 2) menunjukkan bahwa terdapat perbedaan kekerasan email yang bermakna, sehingga dilanjutkan dengan uji post hoc Bonferroni. Uji post hoc Bonferroni menunjukkan bahwa perbedaan nilai kekerasan yang signifikan terjadi antara kelompok $E$ dengan semua kelompok perlakuan $(A, B, C$, dan $D)$, serta antara kelompok $A$ dengan kelompok $C$, $D$ dan $E$, antara kelompok $B$ dengan kelompok $D$ dan $\mathrm{E}$, antara kelompok $\mathrm{C}$ dengan $\mathrm{E}$, serta antara kelompok $\mathrm{D}$ dengan kelompok $\mathrm{E}$. Terdapat juga perbedaan nilai kekerasan yang tidak signifikan antara kelompok $A$ dengan $B$, antara kelompok $B$ dengan $C$, serta antara kelompok $C$ dengan $D$. Nilai kekerasan email pada lama aplikasi 3 menit (A) 
menunjukkan perbedaan yang signifikan terhadap kelompok dengan lama aplikasi 30 menit (C) dan 60 menit (D), tetapi nilai kekerasan antara kelompok 30 menit dan 60 menit tidak menunjukkan perbedaan yang signifikan. Tantangan yang dihadapi pada aplikasi klinis, adalah kemampuan pasien untuk mempertahankan bahan remineralisasi CPP-ACPF selama mungkin di dalam mulut, untuk memperoleh peningkatan nilai kekerasan yang maksimal dengan lama yang optimal maka lama aplikasi yang menguntungkan untuk digunakan pada pemakaian klinis adalah 30 menit jika dibandingkan dengan 60 menit. Waktu tersebut sesuai dengan anjuran pabrik bahwa pasien dianjurkan untuk tidak makan atau minum selama 30 menit setelah aplikasi CPP-ACPF, hal ini dilakukan untuk untuk menjaga kontak antara bahan remineralisasi dengan email gigi.

Proses pembentukan mineral apatit terjadi segera setelah ion kalsium, fosfat, dan fluor berkontak dengan email. Semakin lama aplikasi yang diberikan maka proses remineralisasi akan berlangsung lebih sempurna serta kristal yang terbentuk akan menjadi lebih padat. Pembentukan kristal apatit diawali dengan terjadinya pengendapan kristal dalam ukuran yang kecil dan memiliki kekurangan beberapa susunan ion pembentuknya. Seiring dengan waktu maka beberapa kristal-kristal kecil tersebut akan melebur untuk membentuk kristal yang lebih besar hingga mencapai ukuran yang maksimal, peristiwa ini disebut dengan Ostwald Ripening. Semakin lama waktu pembentukan kristal, maka kristal yang lebih besar dan sempurna akan terbentuk (Gambar 4). ${ }^{2}$
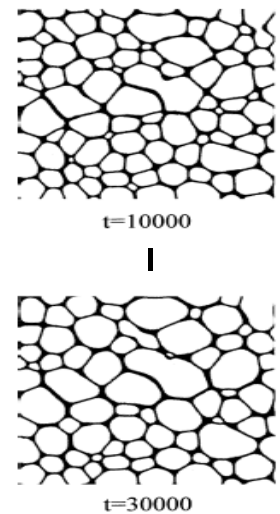

III

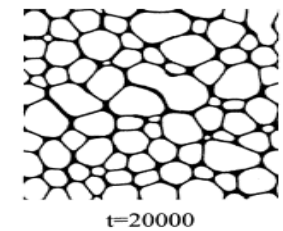

II

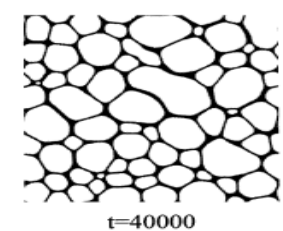

IV
Gambar 4. Ilustrasi perubahan mikrostruktur pada teori Ostwald Ripening. ${ }^{16}$
Proses Ostwald Ripening merupakan dasar pembentukan kristal pada material logam maupun non logam. Proses pertumbuhan kristal ini diawali dengan pengendapan dan pembentukan kristal-kristal dalam berbagai ukuran, kemudian secara perlahan mineral tersebut akan menyempurnakan diri dalam hal ukuran, struktur dan sifat kimia. ${ }^{19}$ Kelarutan dari kristal yang lebih kecil relatif berlangsung dengan cepat, sedangkan pematangannya menjadi kristal yang lebih besar melalui proses yang lebih lama. ${ }^{2,19,20}$

Mekanisme pembentukan kristal apatit juga akan mengikuti aturan yang terdapat pada teori Ostwald Ripening. Kristal email yang terbentuk akan lebih besar dan lebih stabil pada proses remineralisasi yang terjadi lebih lama, sehingga nilai kekerasan email akan meningkat sebanding dengan peningkatan lama aplikasi bahan remineralisasi CPP-ACPF. Berdasarkan uraian diatas dapat disimpulkan bahwa perbedaan lama aplikasi bahan remineralisasi CPP-ACPF berpengaruh terhadap peningkatan kekerasan email. Berdasarkan hasil penelitian ini, peningkatan kekerasan email yang signifikan dengan lama aplikasi yang optimal terjadi pada kelompok dengan lama aplikasi 30 menit.

\section{KESIMPULAN}

Perbedaan lama aplikasi bahan remineralisasi CPP-ACPF berpengaruh terhadap kekerasan email. Peningkatan kekerasan email yang signifikan dengan lama aplikasi yang optimal terjadi pada kelompok dengan lama aplikasi 30 menit.

\section{DAFTAR PUSTAKA}

1. Heymann HO, Swift EJ, Ritter AV. Sturdevant's art and science of operative dentistry. $6^{\text {th }}$ ed. St. Louis: Mosby; 2012. $41-43$.

2. Fejerskov O, Kidd E, editors. Dental caries: the disease and its clinical management. $2^{\text {nd }} e d$. Tunbridge Wells, UK: Blackwell Munksgaard Ltd; 2008. 20, $202-225$.

3. Ballard RW, Hagan JL, Phaup AN, Sarkar N, Townsend JA, Armbruster PC. Evaluation of 3 commercially available materials for resolution 
of white spot lesions. Am J Orthod Dentofacial Orthop. 2013; 143: S78 - 84.

4. Pradeep K, Reader. Remineralizing agents in the non-invasive treatment of early carious lesions. Int J Dent Case Reports. 2011; 1(2): $73-84$.

5. Ivanoff CS, Hottel TL, Garcia-Godoy F. Microhardness recovery of demineralized enamel after treatment with fluoride gel or CPP-ACP paste applied topically or with dielectrophoresis. American Journal of Dentistry. 2012; 25(2).

6. Farooq I, Moheet IA, Imran Z, Farooq U. A review of novel dental caries preventive material: Casein phosphopeptide-amorphous calcium phosphate (CPP-ACP) complex. King Saud University Journal of Dental Sciences. 2013; 4, 47 - 51.

7. Agnihotri $Y$, Pragada NL, Patri G, Thajuraj PK. The effect of cpp-acp remineralization of artificial caries like lesions: an in vitro study. IJMDent. 2011; 2(1): 366 - 369.

8. Bansode PV, Deore R, Pathak S. Evaluation of the effect of casein phosphopeptideamorphous calcium phosphate on tooth enamel demineralized by a carbonated soft drink using micro hardness testing method an in vitro study. Int J Sci Stud 2014; 2(8): 24 -28 .

9. Jaidka S, Somani R, Arora V. Old roads new path: a comparative in vitro remineralising study. J Res Adv Dent. 2015; 4: 1: 84 - 87.

10. Rirattanapong $P, \quad$ Vongsavan $K$, Tepvichaisillapakul M. Effect of five different dental products on surface hardness of enamel exposed to chlorinated water in vitro. Southeast Asian J Trop Med Public Health. 2011; 42: 1293 - 1298.

11. Secilmis A, Dilber D, Gokmen F, Ozturk N, Telatar T. Effects of storage solutions on mineral contents of dentin. Journal of Dental Sciences. 2011 (6):189 - 194.
12. Somani R, Jaidka S, Singh DJ, Arora V. Remineralizing potential of various agents on dental erosion. Journal of Oral Biology and Craniofacial Research 4. 2014: 104 - 108.

13. Taranath A, Pai D, Chakravarthy K. The role of casein phosphopeptide-amorphous calcium phosphate products in remineralization of incipient enamel lesions and its substantivity. J Exp Integr Med. 2014; 4(1): 67 - 70.

14. Patil N, Choudhari S, Kulkarni S, Joshi SR. Comparative evaluation of remineralizing potential or three agents on artificially demineralized human enamel: An in vitro study. J Conserv Dent. 2013; 16: 116 - 20.

15. Vanichvatana S, Auychai P. Efficacy of two calcium phosphate pastes on the remineralization of artificial caries: a randomized controlled double-blind in situ study. International Journal of Oral Science. 2013(5): $224-228$.

16. Fan D, Chen SP, Chen L, Voorhees PW. Phase-field simulation of 2-D Ostwald ripening in the high volume fraction regime. Acta Materialia 2002(50): 1895 - 1907.

17. UlbrichtH, Schmelzer J, Mahnke R, Schweitzer F. Thermodynamics of finite systems and the kinetics of first-order phase transitions. Jerman: Vieweg Teubner Verlag; 1988. 144.

18. Givargizov El. Oriented crystallization on amorphous substrates. New York: Springer Science Business Media New York; 1991. 83.

19. Bonucci E. Calcification in biological system. Boca Raton, Florida: CRC Press; 1992. 14.

20. Baldan A. Progress in Ostwald ripening theories and their applications to nickel-base superalloys. Journal of Materials Science. 2002; 37(11): $2171-2202$. 